\title{
EFFECT OF LUTING AGENT AND SURFACE TREATMENT TYPE ON BOND STRENGTH TO A ZIRCONIA-BASED CERAMIC
}

\author{
Hesham M. Abd El-Megeed*, Ahmed M. Yousri**, Mohammed H. Abd El-Aziz***
}

\begin{abstract}
Statement of The Problem: Debonding is considered as a common cause of failure in zirconia-based restorations. Despite that different resin cements and different surface treatment methods are used, the success rate is still of concern. Purpose: The purpose of this study is to evaluate effect of luting agent type and surface treatment on bond strength to a zirconiabased ceramic. The following hypotheses that will be tested is that: surface treatment and resin cement selection influence the bond strength at the cement-ceramic interface. Materials and methods: In this study, 60 zirconia specimens were treated by two surface treatments (sandblasting and silica coating) then bonded to 60 composite specimens using three resin cements with different kinds of monomers (Bifix QM, Panavia F2.0 and Multilink Automix). Finally all of the specimens underwent aging by thermocycling before measuring the shear bond strength. Results: The highest shear bond strength values were recorded in the group treated by silica-coating (CoJet) and bonded by Panavia F2.0 . The lowest bond strength values were recorded in the group treated by air-particle abrasion and bonded by Bifix QM. Regardless to the resin cement used, totally it was found that CoJet group recorded statistically significant $(\mathrm{P}<0.05)$ higher shear bond strength value than air particle abrasion group. Regardless to the surface treatment, totally it was found that Panavia F2.0group recorded statistically significant $(\mathrm{P}<0.05)$ highest shear bond strength value followed by multilink automix group, then Bifix QM group. Conclusion: Within the limitations of this study, the following conclusion can be drawn: Surface treatment of zirconia surface with CoJet sand gives higher bond strength with the resin cements than $50 \mu \mathrm{m}$ alumina air particle abrasion. Panavia F 2.0 resin cement gives higher bond strength to zirconia than Multilink Automix and Bifix QM.*
\end{abstract}

\section{INTRODUCTION}

The era of considering porcelain-fused to metal (PFM) restorations as the only esthetic solution has ended. Now ceramic materials can be used without metal coping because they are stronger than conventional fieldspathic porcelain ${ }^{(1,2)}$. These materials are either silica- based or non-silica-based materials. Non-silica-based ceramics like zirconia can neither be etched with $\operatorname{acid}^{(3,4)}$ nor can bind to silane ${ }^{(5)}$, so their bond strength is significantly lower than silica-based ceramics, however they have higher strength (reported as 900-1200 MPa for zircona) compared to base metal alloys ${ }^{(6)}$.

Cements are either conventional or adhesive resin cements. Use of resin cements are highly recommended to give translucency, to improve the retention and to strengthen the restoration ${ }^{(7)}$.

Bond strength can be defined as the maximum load per unit area that causes failure on or near the bonded interface of the substrate and the adherend ${ }^{(8)}$. Various bond strength tests are currently used in adhesive dentistry, such as shear, tensile, microtensile and micro-shear bond strength (SBS) tests ${ }^{(9)}$.

Bonding between cement and the restoration is affected by the fluctuation of hot and cold conditions in the oral cavity, so testing the bond strength after thermocycling is very important ${ }^{(10)}$.

\footnotetext{
* Dentist at the Ministry of Health

** Assistant Professor, Department of Crown and Bridge, Faculty of Dental Medicine, Boys, Cairo, Al-Azhar University *** Assistant Professor, Department of Crown and Bridge, Faculty of Dental Medicine, Boys, Cairo, Al-Azhar University
} 


\section{HYPOTHESIS}

The hypothesis of this study was that surface treatment and resin cement selection influence the bond strength at the cement-ceramic interface.

\section{MATERIALS \& METHODS}

One blank disc of Bruxzir zirconia (Glidewell Dental Laboratories; USA) was cut by a microsaw to obtain sixty square-shaped zirconia specimens. The specimens were cleaned in ultrasonic bath filled with distilled water for 30 seconds, then dried by a heat lamp. The specimens were put in sintering tray containing zirconia beads in sintering oven and sintered according to the manufacturer's instructions.

\subsubsection{Specimen Fabrication}

A custom made mold was used to fabricate the composite specimens. A transparent thin glass slab was placed under the mold and the composite was densely packed with condenser then another transparent glass slab was placed above the mold. From each surface, light curing of the composite was carried out through the glass slap for 40 seconds. The mold was dissembled and the specimens were removed.

\section{Specimen grouping}

A total of 60 square-shaped zirconia specimens were divided into two equal main groups of 30 samples. Each according to the type of the surface treatment used. Each group of the two main groups was further subdivided into three equal subgroups of 10 samples each according to the resin cement used (Table 1).
TABLE (1): Grouping of specimens.

\begin{tabular}{|c|c|c|c|}
\hline $\begin{array}{c}\text { Surface } \\
\text { treatment }\end{array}$ & Group & Resin cement & $\begin{array}{l}\text { Number of } \\
\text { specimens }\end{array}$ \\
\hline \multirow{3}{*}{$\begin{array}{c}\text { Air-Particle } \\
\text { Abrasion } \\
\text { Group A }\end{array}$} & $\mathrm{AB}$ & Bifix QM & 10 \\
\hline & AP & Panavia F 2.0 & 10 \\
\hline & $\mathrm{AM}$ & Multilink Automix & 10 \\
\hline \multirow{3}{*}{$\begin{array}{l}\text { Silica coating } \\
\text { Group } S\end{array}$} & SB & Bifix QM & 10 \\
\hline & SP & Panavia F 2.0 & 10 \\
\hline & SM & Multilink Automix & 10 \\
\hline \multicolumn{3}{|c|}{ Total specimens number } & 60 \\
\hline
\end{tabular}

\subsubsection{Surface treatment}

The bonding surfaces of zirconia specimens were treated by intraoral air abrasion device using a custom-made holder to standardize the distance between the nozzle of the device and the zirconia specimens at $10 \mathrm{~mm}$ and the angle at $90^{\circ}$ (Figure 1). In groups $A B, A P$ and $A M$, specimens were treated by APA. The device was filled with $50 \mu \mathrm{m}$ alumina particles which were blasted at pressure of 2.8 bars for 10 seconds. In groups SB, SP and SM, the bonding surfaces of zirconia were silica-coated. The device was filled with $30 \mu \mathrm{m}$ silica-coated alumina particles (Cojet sand) which were blasted at the preset pressure of 2.8 bar for $15 \mathrm{~s}$ at the same distance then marked by green color on one corner.

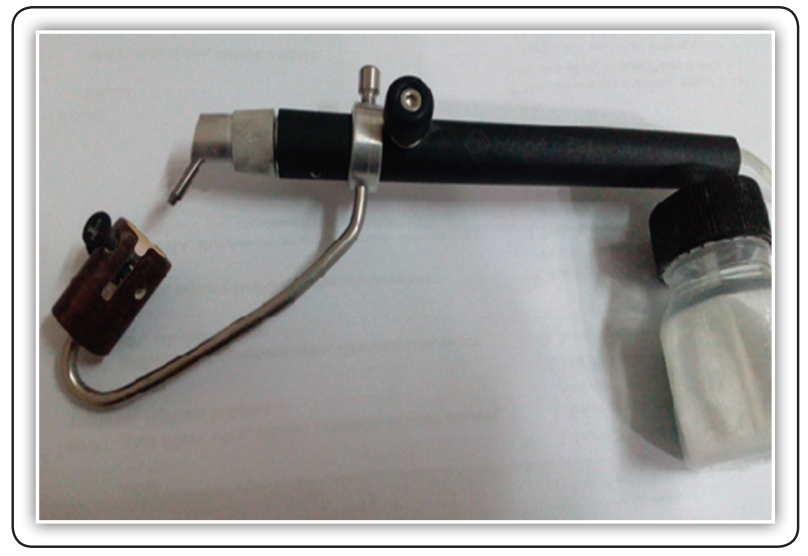

FIG (1) A photograph of a microblaster in the holder, nozzle perpendicular to zirconia specimen 


\subsubsection{Bonding of the specimens}

Cement-specific ceramic bond was applied on each zirconia specimen using a microbrush and was left for 60 seconds to react then excess was dispersed with air stream. The cement was applied directly on zirconia specimens.

Composite specimens were centered above the loaded zirconia specimens by the aid of a split cupper mold and split Teflon mold.

After 30 seconds a microbrush and a scaler were used to remove the excess cement then margins were covered by oxygen protective gel. Resin cements were light cured from each side of the zirconia for 40 seconds per surface

\subsubsection{Thermo-cycling of samples}

Samples were stored in distilled water for 24 hours at $37^{\circ} \mathrm{C}$, then submitted to 1000 thermocycle at temperature between $5^{\circ} \mathrm{C}$ and $55^{\circ} \mathrm{C}$, with $30 \mathrm{sec}$. dwell time in each bath and a $10 \mathrm{sec}$. transfer time.

\subsubsection{Evaluation of shear bond strength}

A testing machine was used to perform the shearing test using a compressive mode of load. The samples were secured to the lower fixed compartment of testing machine by tightening screws and a mono-beveled chisel shaped metallic rod was attached to the upper movable compartment of the testing machine and applied on compositezirconia interface traveling at cross-head speed of $0.5 \mathrm{~mm} / \mathrm{min}$. The load required to debonding was recorded in Newton. Shear bond strength was calculated according to the following equation $\tau=\mathrm{F} / \mathrm{A}$.

\section{RESULTS}

Student t-test where assessed to compare between two studied groups. for normally distributed quantitative variables, Two way (ANOVA) was assessed to show the effect of each factor and the interaction between them. For normally distributed quantitative variables, F-test (ANOVA) was as- sessed to compare between more than two groups. Post Hoc test (Tukey) (LSD) were assessed for pairwise comparisons.

\subsection{Descriptive statistics}

The mean values and standard deviation of shear bond strength (MPa) as function of surface treatments and resin cement type were summarized (Table 2) and graphically drawn (Figure 2). The highest shear bond strength values were recorded in the group treated by silica-coating (CoJet) and bonded by Panavia F2.0 . The lowest bond strength values were recorded in the group treated by airparticle abrasion and bonded by Bifix QM.

TABLE (2): Descriptive statistics of shear bond strength values (MPa) (Mean values \pm SDs as function of surface treatments and resin cements)

\begin{tabular}{|c|c|c|c|}
\hline \multicolumn{2}{|c|}{ Bond strength in MPa } & \multicolumn{2}{c|}{ Surface treatment } \\
\cline { 3 - 4 } & $\begin{array}{c}\text { Silica } \\
\text { coating }\end{array}$ & Sandblasting \\
\hline \multirow{3}{*}{$\begin{array}{c}\text { Resin } \\
\text { Cements }\end{array}$} & Bifix QM & $8.25 \pm 0.76$ & $6.19 \pm 0.90$ \\
\cline { 2 - 4 } & Panavia F2 & $13.39 \pm 1.0$ & $11.29 \pm 0.94$ \\
\cline { 2 - 4 } & $\begin{array}{c}\text { Multilink } \\
\text { Automix }\end{array}$ & $10.40 \pm 1.02$ & $8.08 \pm 0.71$ \\
\hline
\end{tabular}

Regardless to the resin cement used, totally it was found that CoJet group recorded statistically significant $(\mathrm{P}<0.05)$ higher shear bond strength value than air particle abrasion group (Table 3 ).

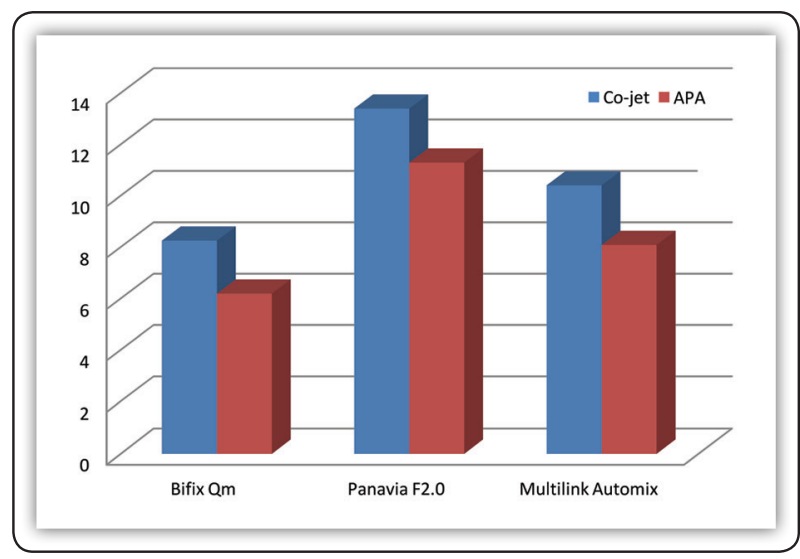

FIG (2) A column chart of total shear bond strength mean values as function of surface treatment. 
TABLE (3) Comparison between the two surface treatments in each resin cement according to bond strength in $\mathrm{MPa}$

\begin{tabular}{|c|c|c|c|c|}
\hline & $\begin{array}{l}\text { Surface } \\
\text { treatment }\end{array}$ & $\begin{array}{l}\text { Bond strength } \\
\text { in } \mathrm{MPa}\end{array}$ & $\mathrm{t}$ & $\mathrm{p}$ \\
\hline \multirow{2}{*}{ Bifix QM } & Silica coating & $8.25 \pm 0.76$ & \multirow{2}{*}{$5.529^{*}$} & \multirow{2}{*}{$<0.001^{*}$} \\
\hline & Sandblasting & $6.19 \pm 0.91$ & & \\
\hline \multirow{2}{*}{ Panavia F2 } & Silica coating & $13.39 \pm 1.0$ & \multirow{2}{*}{$4.818^{*}$} & \multirow{2}{*}{$<0.001^{*}$} \\
\hline & Sandblasting & $11.29 \pm 0.94$ & & \\
\hline \multirow{2}{*}{$\begin{array}{l}\text { Multilink } \\
\text { Automix }\end{array}$} & Silica coating & $10.40 \pm 1.02$ & \multirow{2}{*}{$5.900^{*}$} & \multirow{2}{*}{$<0.001^{*}$} \\
\hline & Sandblasting & $8.08 \pm 0.71$ & & \\
\hline
\end{tabular}

$t, p: t$ and $p$ values for Student t-test for comparing between the two groups

*: Statistically significant at $p \leq 0.05$

Regardless to the surface treatment, totally it was found that Panavia F2.0 group recorded statistically significant $(\mathrm{P}<0.05)$ highest shear bond strength value followed by multilink automix group, then Bifix QM group (Table 4).

TABLE (4): Comparison between the three resin cement in each surface treatments according to bond strength in $\mathrm{MPa}$

\begin{tabular}{|c|c|c|c|c|}
\hline $\begin{array}{c}\text { Surface } \\
\text { treatment }\end{array}$ & $\begin{array}{c}\text { Resin } \\
\text { cement }\end{array}$ & $\begin{array}{c}\text { Bond strength } \\
\text { in MPa }\end{array}$ & t & p \\
\hline \multirow{4}{*}{$\begin{array}{c}\text { Silica } \\
\text { coating }\end{array}$} & Bifix QM & $8.25 \pm 0.76^{\mathrm{c}}$ & & \\
\cline { 2 - 3 } & Panavia F2 & $13.39 \pm 1.0^{\mathrm{a}}$ & \multirow{2}{*}{$76.128^{*}$} & $<0.001^{*}$ \\
\cline { 2 - 3 } & $\begin{array}{c}\text { Multilink } \\
\text { Automix }\end{array}$ & $10.40 \pm 1.02^{\mathrm{b}}$ & & \\
\hline \multirow{4}{*}{ Sandblasting } & Bifix QM & $6.19 \pm 0.90^{\mathrm{c}}$ & & \\
\cline { 2 - 3 } & Panavia F2 & $11.29 \pm 0.94^{\mathrm{a}}$ & \multirow{2}{*}{$90.313^{*}$} & $<0.001^{*}$ \\
\cline { 2 - 4 } & $\begin{array}{c}\text { Multilink } \\
\text { Automix }\end{array}$ & $8.08 \pm 0.71^{\mathrm{b}}$ & & \\
\hline
\end{tabular}

$F, p: F$ and $p$ values for ANOVA test, Sig. bet. groups was done using Post Hoc Test (Tukey)

$p_{1}: p$ value for comparing between Bifix $Q M$ and Panavia F2

$p_{2}: p$ value for comparing between Bifix $Q M$ and Multilink Automix

$p_{3}: p$ value for comparing between Panavia F2 and Multilink Automix

*: Statistically significant at $p \leq 0.05$
TABLE (5): Two factorial analysis of variance ANOVA test of significance comparing variables affecting shear bond strength mean values

\begin{tabular}{|c|c|c|c|c|c|}
\hline $\begin{array}{c}\text { Bond } \\
\text { strength in } \\
\text { MPa }\end{array}$ & DF & SS & MS & F & P value \\
\hline $\begin{array}{c}\text { Surface } \\
\text { treatment }\end{array}$ & 1 & 69.984 & 69.984 & $86.861^{*}$ & $<0.001^{*}$ \\
\hline $\begin{array}{c}\text { Resin } \\
\text { cements }\end{array}$ & 2 & 266.032 & 133.016 & $165.093^{*}$ & $<0.001^{*}$ \\
\hline Interaction & 2 & 0.196 & 0.098 & 0.122 & 0.886 \\
\hline
\end{tabular}

*: Statistically significant at $p \leq 0.05$

\section{DISCUSSION}

There is a great interest in using zirconium oxide-based restorations in dentistry due to its high mechanical properties, esthetics and biocompatibility ${ }^{(11)}$. However, a strong bond with the luting agent is needed for a long lasting restoration. It has been previously demonstrated that the bond strength of resin-based materials to acid-resistant ceramics, especially zirconia, is neither durable nor stable because they resist etching with acids and they contain no silica, so they can't bind to silane ${ }^{(12,13)}$.

Air particle abrasion was recommended by many authors who claimed that the application of this surface treatment results in obtaining high bond strength between zirconia and resin cements ${ }^{(14)}$.

Silica coating is advocated by many authors to increase the bond strength between zirconia and resin cements by roughening the surface of zirconia and embedding silica particles in the zirconia surface as proved by energy dispersive $\mathrm{X}$-ray spectroscopy $(\mathrm{EDS})^{(15)}$. Another view exist that because of the increased hardness of zirconia, the embedded silica are not enough to obtain effective silanization and even the formed siloxane network may be liable to hydrolytic degeneration ${ }^{(16,17)}$.

To evaluate the effect of cement type, three resin cements with different adhesive monomer content were used. 
Thermocycling was used in this study owing to the fact that thermocycling results in the highest clinically relevant stress when testing the durability of resin bond and affects the bond strength between zirconia and resin cement more than water storage at a constant temperature ${ }^{(18,19)}$.

Shear bond strength test is one of the commonly used tests because it is easy to be done, fast and it gives an indication about the behavior of the cemented restoration to lateral and axial forces ${ }^{(20,21)}$, but it is criticized by that it results in non-uniform interfacial stresses, so rate of load application and cross sectional surface area should be standardized ${ }^{(22)}$.

The data of this study revealed significant differences between bond strength values obtained using two different surface treatments and three different resin cements on the bond strength at cement-ceramic interface, so the proposed hypothesis was accepted by the results of this study.

The results of the present study showed that that there were statistically significant differences in the mean shear bond strength between Panavia F2.0 group, Bifix-QM group and Multilink Automix group. This can be explained by that these resin cements differ in the composition of the monomer, solvent or initiator ${ }^{(23)}$.

Regardless of the used surface treatment, Panavia F2.0 recorded the highest shear bond strength. This can be explained by the ability of the phosphate ester monomer in MDP to bond directly to metal oxides such as zirconium oxides ${ }^{(24)}$.

Bifix QM group recorded the lowest shear bond strength. This was attributed to the presence of some disadvantages in Bis GMA molecule such as water sorption, high viscosity and low degree of conversion. Diluents were incorporated into the material aiming to overcome the problem of high viscosity, but this can result in higher shrinkage stresses ${ }^{(25,26)}$.
The results of the present study, irrespective of the resin cement used, silica coating group showed statistically significant improvement in bond strength than air particle abrasion group.

Mechanical methods of surface treatment such as air particle abrasion and silica coating cause roughening of the surface and creation of microretentive sites and reactive hydroxyl groups, but only silica coating causes impediment of silica particles into the outer surface of zirconia which in turn react with silane group. Silane group contains three methoxy groups that form three sianol groups after reaction with water. These sianol groups undergo another reaction with the silica embedded in the zirconia surface transforming into siloxane network which is stable at high temperature ${ }^{(27)}$.

According to the results of these studies, the combination of tribochemical silica coating and an MDP containing resin cement would be the best protocol for bonding to zirconia framework. However, longer thermocycling intervals and dynamic loading should be done in further researches to be more predictive to the long term durability of bonding. It should be considered that oral environment is more complex than in vitro conditions. Teeth are under continuous stresses of different types like cyclic loading, so aging under combination of many stressful conditions should be considered.

\section{CONCLUSION}

Within the limitations of this study, the following recommendations can be made:

1. Surface treatment of zirconia surface with CoJet sand gives higher bond strength with the resin cements than $50 \mu \mathrm{m}$ alumina air particle abrasion.

2. Panavia F 2.0 resin cement gives higher bond strength to zirconia than Multilink Automix and Bifix QM. 


\section{REFERENCES}

1. Raigrodski T. Contemporary materials and technologies for all-ceramic fixed partial dentures. J of Prosthet Dent. 2004; 92: 557-62.

2. Seiji B. Reliability and properties of core materials for all-ceramic dental restorations. J of Dent Sci Rev 2008; 44:3-21

3. Kern M, Wegner M. Bonding to zirconia ceramic. J of Dent Mater 1998;14:64-71.

4. Blatz B, Sadan A and Kern M. Resin-ceramic bonding. J of Dent. Rest. 2003 89:268-74.

5. Thompson Y, Stoner R, Piascik R and Smith R. Adhesion to zirconia and other non-silicate ceramics. J. Dent Mater. $2011 ; 27: 71-82$.

6. Stefano G, Van P and Jonathan L. A new classification system for all-ceramic and ceramic-like restorative materials. J of prosthodont. 2015;3:227-36.

7. Edelhoff D and Ozcan M. To what extent does the longevity of fixed dental prostheses depends on the function of the cement. J of Clin. Oral Implant Rest. 2007;18:193-204

8. Xiang Z, Zhi C, Hui W and Ying J. Influence of different adherend materials and combinations on in vitro shear bond strength. J of Dent Mat 2013; 32: 622-627.

9. Wegner $\mathrm{S}$ and Kern M. Long-term resin bond strength to zirconia ceramic. J of Adhes. Dent. 2000;2:139-47.

10. Lee T, Ahn J, Shim J, Han C and Kim S. Influence of cement thickness on resin-zirconia microtensile bond strength. J of Adv. Prosthodont. 2011;3:119-25.

11. Cavalcanti A, Foxton R, Watson T, Oliveira M and Giannini M. Y-TZP ceramics: Key concepts for clinical application. J of Oper. Dent. 2009;34:344-51.

12. Valandro L, Özcan M, Amaral R, Leite P and Bottino M. Microtensile bond strength of a resin cement to silicacoated and silanized In-Ceram Zirconia before and after aging. J of fixed Prosthodont. 2007;20:70-2.

13. Ardlin B. Transformation-toughened zirconia for dental inlays, crowns and bridges: chemical stability and effect of low temperature aging on flexural strength and surface structure. J of Dent. Mater. 2002;18:590-5.

14. Wolfart F, Lehmann L, Wolfart S, and Kern M. Durability of the resin bond strength to zirconia ceramic after using different surface conditioning methods. J of Dent. Mat. 2007;23:45-50.
15. Valandro F, Ozcan M, Bottino C, Bottino A, Scotti R and Bona D. Bond strength of a resin cement to highalumina and zirconia-reinforced ceramics. $\mathrm{J}$ of Adhes Dent. 2006 ;8:175-81.

16. Matinlinna J, Heikkinen T, Ozcan M, Lassila LV and Vallittu P. Evaluation of resin adhesion to zirconia ceramic using some organosilanes. J of Dent. Mater. 2006; $22: 824-31$.

17. Denry I. State of the art of zirconia for dental applications. J of Dent. Mater. 2008:24:3:299-307.

18. Gale M and Darvell B. Thermal cycling procedures for laboratory testing for dental restorations. J. of Adhe. Dent 1999;27:89-99.

19. Wegner S, Gerdes W and Kern M. Effect of different artificial aging conditions on ceramic-composite bond strength. J of Prosthodont 2002;15: 267-72.

20. Mahmoud S, Abdel Kader M, Zaher A, Ghazy M and Abdelaziz K. Bonding of resin composite to tooth structure of uremic patients receiving hemodialysis. J of Adhes Dent 2008; $10: 335-8$

21. Blatz M, Chiche $\mathrm{G}$ and Holst S. Influence of surface treatment and simulated aging on bond strengths of luting agents to zirconia. J of Invest. and Clin. Dent. 2007;38:745-53.

22. Özkurt Z, Kluazazog E and Ahmet A. In vitro evaluation of shear bond strength of veneering ceramics to zirconia. J of Dent. Mater. 2010;29:138-46.

23. 23 Khalid M, Nasser M, Abdulrahman S. Al-Shehri and Adel M. Bonding quality of contemporary dental cements to sandblasted esthetic crown copings. J of Invest. Dent. 2012:3:142-7.

24. Floyd C and Dickens S. Network structure of Bis-GMAand UDMA-based resin systems. J of Dent. Mater. 2006;22:1143-9.

25. Burgess J, Ghuman T and Cakir D. Self-adhesive resin cements. J of Esthet. Restor. Dent. 2010;22:412-9.

26. Ozcan M and Vallittu P. Effect of surface conditioning methods on the bond strength of luting cement to ceramics. J of Dent. Mater. 2003;19:725-31

27. Han I, Kang D, Chung C, Choe H. and Son M. Effect of various intraoral repair systems on the shear bond strength of composite resin to zirconia. J of Adv. Prosthodont. 2013;5:248-55. 